\title{
Human and Non-Human Primate Intestinal FcRn Expression and Immunoglobulin G Transcytosis
}

Pamela J. Hornby • Philip R. Cooper • Connie Kliwinski • Edwin Ragwan • John R. Mabus • Benjamin Harman • Suzanne Thompson • Amanda L. Kauffman • Zhengyin Yan • Susan H. Tam • Haimanti Dorai • Gordon D. Powers • Jill Giles-Komar

Received: 4 June 2013 / Accepted: 12 September 2013 / Published online: 26 September 2013

(C) The Author(s) 2013. This article is published with open access at SpringerLink.com

\begin{abstract}
Purpose To evaluate transcytosis of immunoglobulin G (lgG) by the neonatal Fc receptor ( $F(R n)$ in adult primate intestine to determine whether this is a means for oral delivery of monoclonal antibodies (mAbs).

Methods Relative regional expression of FcRn and localization in human intestinal mucosa by RT-PCR, ELISA \& immunohistochemistry. Transcytosis of full-length mAbs (sandwich ELISAbased detection) across human intestinal segments mounted in Ussing-type chambers, human intestinal (caco-2) cell monolayers grown in transwells, and serum levels after regional intestinal delivery in isoflurane-anesthetized cynomolgus monkeys.

Results In human intestine, there was an increasing proximal-distal gradient of mucosal FcRn mRNA and protein expression. In cynomolgus, serum mAb levels were greater after ileum-proximal colon infusion than after administration to stomach or proximal small intestine ( $1-5 \mathrm{mg} / \mathrm{kg})$. Serum levels of wild-type mAb dosed into ileum/proximal colon (2 mg/kg) were $124 \pm 104 \mathrm{ng} / \mathrm{ml}(n=3)$ compared to $48 \pm 48 \mathrm{ng} / \mathrm{ml}(n=2)$ after a non-FcRn binding variant. In vitro, mAb transcytosis in polarized caco-2 cell monolayers and was not enhanced by increased apical cell surface lgG binding to FcRn. An unexpected finding in primate small intestine,
\end{abstract}

was intense FcRn expression in enteroendocrine cells (chromagranin A, GLP-I and GLP-2 containing).

Conclusions In adult primates, FcRn is expressed more highly in distal intestinal epithelial cells. However, mAb delivery to that region results in low serum levels, in part because apical surface FcRn binding does not influence mAb transcytosis. High FcRn expression in enteroendocrine cells could provide a novel means to target mAbs for metabolic diseases after systemic administration.

KEY WORDS drug delivery · epithelial cell · Fc receptor . monoclonal antibody · oral bioavailability

\section{INTRODUCTION}

Monoclonal antibody (mAb) therapeutics are not administered orally due to their degradation by digestive enzymes in the intestinal lumen and low intestinal permeation, resulting from their large molecular size and high polarity. However, in perinatal mammals, intestinal transepithelial and transplacental transport of immunoglobulin $\mathrm{G}(\mathrm{IgG})$ is via the neonatal $\mathrm{FC}_{\mathrm{C}}$
P. J. Hornby • P. R. Cooper • E. Ragwan • J. R. Mabus • B. Harman • A. L. Kauffman • S. H. Tam • H. Dorai • G. D. Powers • J. Giles-Komar Biologics Research, Biotechnology CoE, Janssen Pharmaceutical J\&J Radnor, Pennsylvania 19087, USA

\section{Kliwinski}

Biologics Pharmacology and Toxicology, Biotechnology CoE Janssen Pharmaceutical J\&J, Radnor, Pennsylvania I9087, USA

\section{S. Thompson}

Preclinical Affairs Ethicon EndoSurgery, Inc. Preclinical R\&D

Cincinnati, Ohio 45242, USA

Z. Yan

Discovery Sciences, Janssen Pharmaceutical J\&J

Welsh \& McKean Roads, PO Box 776

Spring House, Pennsylvania 19422, USA

\author{
P. J. Hornby \\ Biologics Research, Biotechnology CoE., Janssen Pharmaceutical \\ Companies of Johnson \& Johnson, Welsh \& McKean Roads \\ Spring House, Pennsylvania 19477, USA
}

Present Address:

P. J. Hornby $(\square)$

Translational Models Team, Cardiovascular Metabolism Therapeutic R\&D., Janssen Pharmaceutical Companies of Johnson \& Johnson Spring House, Pennsylvania 19422, USA

e-mail: PHornby@its.jnj.com 
receptor (FcRn; also Brambell receptor). This Fc receptor was initially discovered in the neonatal rat intestine (1-4) and it resembles the major histocompatibility complex class I antigens in that it has a heavy chain transmembrane glycoprotein associated with a light chain $\beta 2$-microglobulin (5).

In the rodent intestinal epithelium, high levels of FcRn expression and IgG transport are restricted to the suckling period (6-8) during which time it is highly active, accounting for $\sim 80 \%$ of IgG uptake from the duodenum (9). In contrast, in primates, FcRn is expressed in the intestine in villous enterocytes throughout adult life $(10,11)$. This has led to decades of speculation that targeting FcRn could enable oral delivery of mAbs in humans. To date, evaluation of human FcRn-mediated IgG transcytosis has been limited to overexpressing human FcRn epithelial cell lines or transgenic mice $(9,12,13)$. Rodent FcRn-mediated oral delivery has only been demonstrated in suckling rat pups, for example, in a report that oral delivery of a FSH-human Fc domain fusion molecule resulted in systemic levels that retained functionality (14). However, several factors combine to overestimate the apparent IgG oral bioavailability in neonates, such as reduced proteolysis of $\mathrm{IgG}$ by trypsin (15), increased endocytotic mechanisms in neonatal enterocytes (16) and immature mucosal barriers until after weaning (17). Thus, while it is useful mechanistically to study neonatal rodent intestinal FcRn, this model would not be predictive of oral bioavailability in adult humans. There are no reports of in vivo assessment of FcRn distribution and $\mathrm{mAb}$ oral bioavailability in the primate intestine, to our knowledge. However, bronchiole delivery of an erythropoietin-Fc fusion protein to the non-human primate airway resulted in systemic bioavailability (18). Therefore, we rationalized that if bronchial epithelial cells could transport mAb from apical to basolateral in primates in vivo, an investigation into similar FcRn functionality in the adult primate intestine could support this potential mechanism for oral delivery of mAbs.

To address this, we used mAbs with Fc mutations designed to modulate binding to $\mathrm{FcRn}$ combined with a detection assay to quantify the presence of transported full-length mAb directly. Fc mutations have been applied to IgG-based therapeutics to exploit FcRn functions and selectively target tissues (19). For example, amino acid replacements of residues in the $\mathrm{CH} 2-3$ region of $\mathrm{Fc}_{\mathrm{C}}$ increase $\mathrm{FcRn}$ binding affinity and are useful to increase its circulating serum half-life $(19,20)$. Conversely, a Fab that contains a polyethylene glycol moiety in place of an Fc region is useful because it reduces transplacental transfer of the molecule (21). Therefore, the present study used wild-type (WT) $\mathrm{mAb}$ and engineered FcRn binding affinity variants in vitro, in isolated human intestine and in vivo in cynomolgus monkeys by direct intestinal delivery to assess whether effective FcRn-mediated transcytosis could contribute to intestinal mAb uptake. In addition, regional FcRn expression and immunohistochemical localization was determined using an anti-human FcRn polyclonal antibody.
These experiments illustrated regional intestinal epithelial FcRn expression and demonstrated that some mAb apical-tobasal transcytosis occurred, but could not address whether apical surface FcRn engages mAb from the intestinal lumen. Brambell's original hypothesis is that IgG binds to FcRn in the acidified conditions of the endosome and $\operatorname{IgG}$ is internalized after pinocytosis (i.e. not necessarily after cell surface FcRn binding). However, in human intestinal cells apical FcRn expression is noted $(12,22)$ with increased FcRn expression in apical endocytic pits after exposure to $\operatorname{IgG}(4)$. In addition, many investigators incubate $\mathrm{mAb}$ in acidic $\mathrm{pH}$ to enhance $\mathrm{FcRn}_{\mathrm{C}}$ cell surface binding in vitro (11-13), even though intracellular FcRn is more prevalent (11). If intestinal lumen exposure to $\mathrm{mAb}$ results in FcRn binding on the apical surface of enterocytes, then this would be an attractive mechanism to target for orally delivered mAbs in humans. Therefore, the expression and contribution of cell surface FcRn to mAb transcytosis was assessed in endogenously FcRn-expressing human intestinal caco-2 cells.

\section{MATERIALS AND METHODS}

All animal studies were performed in accordance with the Federal Animal Welfare Act and protocols were approved by the Institutional Animal Care and Use Committee at Janssen Pharmaceutical R\&D, Biotechnology Center of Excellence. Human intestinal tissue, which was not used for transplant purposes, was transported and processed as soon as possible after death. Donor tissue met the following qualification criteria: male or female, $\leq 65$ years of age, with no known history of gastrointestinal disease or alcohol abuse, and having accompanying demographics information.

\section{Monoclonal Antibody Isotype and Engineered mAb FcRn Binding Affinity}

Human mAbs with mutations on IgG1 or IgG2 isotype were generated in house. The complimentary determining regions were to respiratory syncytial virus (RSV; also referred to as $\mathrm{B} 21 \mathrm{M}$ ) on an IgG1 isotype or to an endogenous growth factor on a 1 gG2 isotype (M13 and M15). Variants of anti-RSV IgG1 WT were generated by mutating asparagine at position 434 to alanine (23) or the histidine at position 435 to alanine $(24,25)$ and termed anti-RSV N434A and H435A, respectively. A variant (termed M15 M428L) was generated by mutating a methionine at position 428 to leucine (26). Their binding affinities to $\mathrm{FcRn}$ were determined at $p \mathrm{H} 6.0$, since $\mathrm{FcRn}_{\mathrm{C}}$ is localized in the acidified endosomes in intestinal epithelial cells (11), which favors IgG-FcRn binding and protects the IgG from lysosomal degradation. Binding at $p \mathrm{H} 7.4$ was expected to be negligible. Table I describes the binding affinities to human FcRn or cynomolgus FcRn by Surface Plasmon Resonance methodology (27), as described 
Table I mAb Binding Affinity to Human and Cyno FcRn at $p \mathrm{H} 6.0$ and $\mathrm{pH} 7.4$

\section{I.0 $\mu \mathrm{M}$ \\ previously (9). A similar rank order of mAb variant affinity was obtained for binding to both cyno and human $\mathrm{FCRn}$ at $p \mathrm{H} 6.0$ (Table I), with variants N434A and M428L showing increased the affinity to FcRn compared to WT and loss of binding in variant $\mathrm{H} 435 \mathrm{~A}$.}

\begin{tabular}{|c|c|c|c|c|c|}
\hline \multirow[t]{3}{*}{ mAb Name } & \multirow[t]{3}{*}{ Isotype \& Mutation } & \multicolumn{4}{|c|}{ Affinity to $F_{C} R n\left(K_{D}\right.$ in $\left.n M\right)$} \\
\hline & & \multicolumn{2}{|c|}{$\mathrm{pH} 6.0$} & \multicolumn{2}{|c|}{$\mathrm{pH} 7.4$} \\
\hline & & Cyno & Human & Cyno & Human \\
\hline Anti-RSV B2IM & $\operatorname{lgG} \mid \mathrm{WT}$ & 447 & 520 & * & * \\
\hline Anti-RSV B2IM & $\lg G \mid N 434 A$ & 109 & 134 & * & * \\
\hline Anti-RSV B2IM & $\operatorname{lgG} \mid \mathrm{H} 435 \mathrm{~A}$ & * & * & * & * \\
\hline Growth Factor MI3 & $\lg G 2 \mathrm{WT}$ & | | | & 125 & * & * \\
\hline Growth Factor MI5 & $\lg G 2 \mathrm{M} 428 \mathrm{~L}$ & 58 & 50 & * & * \\
\hline
\end{tabular}

\section{FcRn Expression and mAb Transcytosis in Human Intestine}

Human donor intestines from a 24-year-old female Hispanic, a 47-year-old African American male and a 49-year-old African American female were obtained shortly after death (due to stroke/intracranial bleed). Intestinal mucosa was collected and either snap frozen or added to $500 \mu \mathrm{l}$ M-PER solution in lysis tubes for mRNA and protein expression, respectively. Full thickness intestinal segments were fixed flat between biopsy sponges in $10 \%$ neutral buffered formalin and paraffin imbedded.

\section{mAb Transcytosis in Isolated Human Intestine}

Muscle-stripped segments were rapidly mounted in Ussingtype flux chambers and after several washes in Krebs-Ringer bicarbonate (KRB) buffer at $p \mathrm{H} 7.4$, incubated on the mucosal side with atenolol, a control compound to determine permeability, co-mixed with $\mathrm{mAb}$ at $p \mathrm{H}$ 6.5. Samples of serosal side media $(50 \%$ rat serum and $\mathrm{KRB}$ buffer at $p \mathrm{H} 7.4)$ were assayed by LC-MS/MS for atenolol, a paracellular permeability marker, by standard analytical methods. Standards were prepared by serial dilution into matrix matched to the mucosal side (KRB buffer $\mathrm{pH} 6.0$ in a six point concentration range of 5$500 \mathrm{nM}$ ) and serosal side (KRB buffer $\mathrm{pH}$ 7.4: rat serum 1:1 v/ $\mathrm{v}$, in a seven point concentration range of 5-5,000 nM) samples. Mucosal side aliquots were diluted 500-fold with KRB buffer $\mathrm{pH}$ 6.0, but serosal side samples were not diluted. Samples and standards were quenched in a 1:2 proportion with acetonitrile, vortexed for $5 \mathrm{~min}$, and then centrifuged at 13,000 rpm for $10 \mathrm{~min}$. The supernatant was collected, diluted 1:3 with water, and analyzed by liquid chromatography. Thermo Hypersil BDS C18 $(30 \times 2.0$ mm i.d., $3 \mu \mathrm{m})$ was used with guard column M.P. Buffer $(25 \mathrm{mM}$ ammonium formate buffer, $\mathrm{pH} 3.5$ ) at a flow rate of $300 \mu \mathrm{L} /$ minute and aqueous reservoir (90\% water, 10\% buffer) and organic Reservoir $(90 \%$ acetonitrile, $10 \%$ buffer) for a total run time of $3.5 \mathrm{~min}$. Analysis by mass spectrometer (PE SCIEX API 3000, multiple reaction monitoring) was for $10 \mu \mathrm{l}$ samples using turbo ionspray interface for $3.5 \mathrm{~min}$ duration. Based on the LC-MS analysis of atenolol concentration on the mucosal and serosal sides, the atenolol permeation calculated based on apparent permeability coefficient, $\operatorname{Papp}=(\delta \mathrm{Cr} / \delta \mathrm{t}) \times \mathrm{Vr} /\left(\mathrm{A} \times \mathrm{C}_{0}\right)$, was confirmed to be within the expected range for all segments up to $180 \mathrm{mins}\left(\mathrm{Papp}<7 \times 10^{-6} \mathrm{~cm} / \mathrm{s}\right.$ in small intestine and $<$ $10 \times 10^{-6} \mathrm{~cm} / \mathrm{s}$ for colon).

\section{Detection of Full-Length $m A b$}

Serosal samples were analyzed for intact mAb based on the MesoScale Discovery (MSD) electrochemiluminescent format. For detection of full-length mAb, an anti-idiotypic antibody specific to the mAbs (M15 or anti-RSV) were labeled with Sulfo-NHS-LC-Biotin and used as capture antibody on streptavidin-coated MSD plates. A pan anti-human IgG1/ IgG2 antibody labeled with MSD Sulfo-TAG NHS Ester was used as the detection antibody. Relative Luminescent Units (RLU) were measured using a Sector Imager 6000 reader and Discovery Workbench software (MSD). Acceptance criteria were a minimum of two fold over background signal: noise ratio for samples, and 70-130\% recovery on spiked QC duplicates. Based non-linear regression analysis of standard curves (GraphPad Prism version 5), mAb unknown concentrations were back-calculated by extrapolation from the standard curve. The quantification range was determined to be between 0.05 and $500 \mathrm{ng} / \mathrm{ml}$.

\section{Human FcRn Protein Expression}

An FcRn ELISA on human donor mucosa was performed on plates coated with affinity-purified goat anti-human FcRn antibody $(1.0 \mu \mathrm{g} / \mathrm{ml}$, prepared in-house $)$ and incubated in rat anti-human FcRn antibody $(5 \mu \mathrm{g} / \mathrm{ml})$ and then alkaline phosphatase conjugated goat anti-rat antibody at 1:10,000 (Jackson Immunoresearch; West Grove, PA, USA). Using a standard curve $(15.6-1,000 \mu \mathrm{g} / \mathrm{ml}$ BSA; Micro BCA 
Bradford Assay Kit, Thermoscientific; Rockford, IL) OD values from duplicate samples were back-calculated and reported as FcRn/mg of total protein.

\section{Intestinal FcRn Immunohistochemistry}

Paraffin-imbedded $5 \mu \mathrm{m}$ sections were cut from full-thickness intestine harvested from monkey and human donors, and from human tissue bank (MTB-311 and MTB-316; Qualtek Molecular Labs, Goleta, CA) and dried on glass slides $\left(60^{\circ} \mathrm{C}\right)$. Steam heat induced epitope recovery (SHIER) system was used with pretreatment in the solutions in the capillary gap in the upper chamber of a Black and Decker Steamer (28). Sections were incubated in affinity purified rat anti-human FcRn polyclonal antibody (generated in house) or rabbit antihuman FcRn, (H-274, Santa Cruz Biotechnologies) or control (non-immune) IgG then stained using Avidin Biotin Complex immunohistochemistry (9). For colocalization of FcRn with enteroendocrine (EE) hormones in human tissue, primary antibodies were rabbit anti-human GLP-1 (7-37) and GLP2 (Phoenix Pharmaceuticals, Burlingame CA), anti-CCK-8 (Sigma, St Louis MO) and anti-Gastrin (Dako, Denmark) using a secondary donkey anti-rabbit IgG (Alexa fluor555 at 1:500, Invitrogen, Grand Island, NY). Colocalization of EE hormones with FcRn was by creating a sandwich of four adjacent sections consisting of rat IgG negative control, antihuman FcRn, anti-EE, and rabbit IgG negative control. FcRn and EE-stained sections remain adjacent, separated by $5 \mu \mathrm{m}$. Representative images using Koehler illumination were obtained with an Olympus Microfire digital camera (M/N S97809) attached to an Olympus BX60 microscope.

\section{Rat Intestinal mAb Uptake In Vivo}

In rat pups under isoflurane surgical inhalation anesthesia a midline laparotomy was performed and a $27 \mathrm{~g}$ needle was placed directly into the duodenum, ileum and proximal colon, approximately $1 \mathrm{~cm}$ distal to the cecum, as reported in detail (9). After bolus intestinal dosing of anti-growth factor $(1.0 \mathrm{mg} /$ $\mathrm{kg}$ diluted to $10 \mathrm{ml} / \mathrm{kg}$ in PBS) the needle was removed and a small ligating clip placed to prevent any leakage into the abdominal cavity. Blood $(\sim 200 \mu \mathrm{l})$ was collected at 5 and 90 min post-dosing from the retro-orbital venous plexus. The serum was separated and frozen at $-80^{\circ} \mathrm{C}$ until assayed, as reported above. After euthanasia, small intestinal full thickness tissue $(\sim 1 \mathrm{~cm})$ from rat pups and mucosal scrapings from their dams were snap frozen for mRNA analysis (below).

\section{Cynomolgus Regional Gastrointestinal mAb Uptake In Vivo}

To determine differences in gastrointestinal regional $\mathrm{mAb}$ uptake, eight monkeys (7 male and 1 female; weight $4.3-7.3 \mathrm{~kg}$ ) received $\mathrm{mAb}$ delivered to different regions of the GI tract (1$5 \mathrm{mg} / \mathrm{kg}$ diluted in $10 \mathrm{mls}$ PBS) as shown in Table II. In those monkey receiving gastrointestinal dosing on more than one occasion, mAbs were delivered minimally invasively by oral gavage to the stomach $(n=3 ; 2.5 \mathrm{mg} / \mathrm{kg} \mathrm{mAb})$ or by videogastroscopy using a flexible pediatric endoscope (Olympus GIF-XP160 Video Gastroscope; $n=6$; $1-5 \mathrm{mg} / \mathrm{kg}$ ) to the upper intestine, while monkeys were under isoflurane surgical anesthesia. During videogastroscopy, duodenal mucosal biopsies were obtained using endoscopic cup biopsy forceps that were fixed in $10 \% \mathrm{NBF}$ used for FcRn immunohistochemistry. Blood draws were pre-administration, 5, 90 mins and 4, 24, and 48 hrs. post-endoscopy. In three monkeys femoral vein bolus of $0.05 \mathrm{mg} / \mathrm{kg}$ anti-growth factor was administered with blood draws from 1.5 to $504 \mathrm{~h}$ for determination of circulating half-life of the higher FcRn binding affinity variant in primates. The individual concentration-time profile was analyzed using non-compartmental analysis (NCA) by Winnonlin (v5.2). The terminal elimination rate constant $(\mathrm{lz})$ was determined by leastsquared regression of log-linear transformed data of the terminal phase. The half-life (t1/2) was estimated by natural $\log 2$ times reciprocal lz.

Acute delivery of $\mathrm{mAb}$ in isoflurane-anesthetized animals involved a midline laparotomy and direct infusion into intestines through a 5-ml syringe with butterfly angiocatheter. Following bolus administration in different intestinal regions blood draws (pre-, 5 and 90 mins) and intestinal fluid (90 mins) were taken prior to animals being euthanized. Resected intestinal segments (post-mortem) full-thickness intestine and mucosal biopsies from proximal, mid and distal small intestine were placed in 10\% neutral buffered formalin for immunohistochemistry (as described for human tissue above). The concentration of $\mathrm{mAb}$ in intestinal fluid at termination (diluted 1:1 in monkey serum containing protease inhibitor and centrifuged 3,500 rpm for 10 mins) and in the serum was detected based on the MSD electrochemiluminescent format (as described above).

The predicted blood volume for the monkey gender and weight of cynomolgus macaques was estimated from graphs reported in (29). Fractional uptake at $90 \mathrm{~min}$ after intestinal dosing was calculated based on the concentration in the serum for each animal that was converted into the amount in the total blood compartment. The percentage mAb in serum of the amount delivered into the intestines was considered the fractional uptake into that compartment. However, at 90 mins the $\mathrm{mAb}$ would be distributed in the GI mucosa, lamina propria, lymph and within vascular endothelial cells and therefore factional serum uptake does not take into account total tissue distribution.

\section{Regional Intestinal FcRn mRNA Expression from Rat, Monkey and Human}

Mucosa from human donor, monkey and adult rat intestine and full thickness segments from rat pups were homogenized 


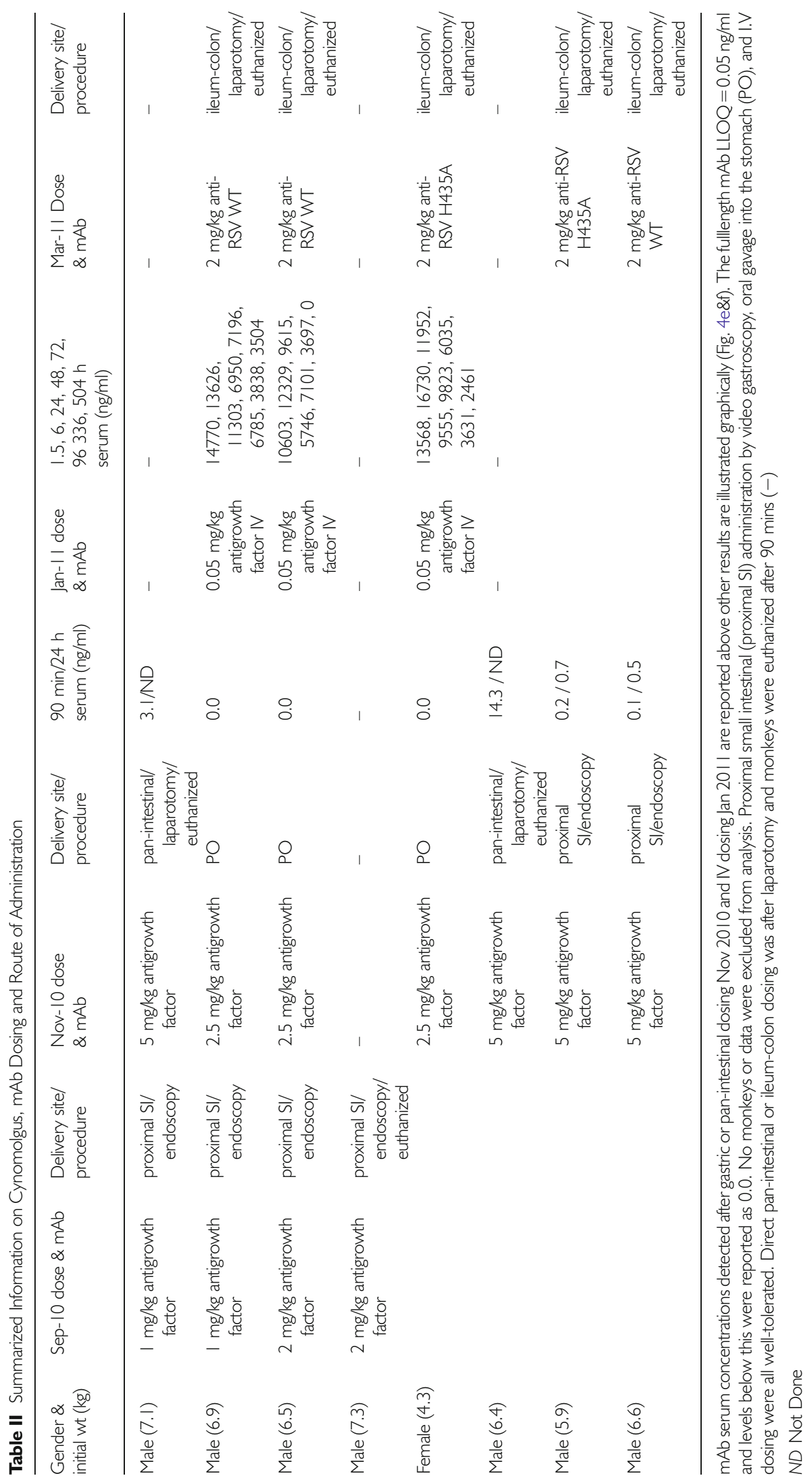


for total RNA purification (RNeasy Mini Kits, QIAGEN, Valencia, CA, USA). The RNA quality was confirmed (RNA Nano chip, Agilent Technologies; Waldbronn, Germany) using the Agilent RNA 6000 (Nano Reagents Part I, Agilent Technologies; Vilnius, Lithuania) and run on an Agilent 2100 bioanalyzer. The concentration was determined by A260 readings and $0.3-1 \mu \mathrm{g}$ RNA from each sample was reverse transcribed to cDNA (Applied Biosystems; Carlsbad, CA, USA). Within a species, the same amount of RNA was added to the cDNA setup.

TaqMan primers and probes (Applied Biosystems) for human and rat HPRT; human, rat, and rhesus GAPDH; human, rat, and rhesus FcRn were run in triplicate for RT-PCR. The CT values generated from human and rat lysates were normalized to human and rat GAPDH and HPRT, respectively. For absolute quantification of the number of FcRn molecules per ng RNA, a known amount of plasmids carrying human FcRn genes were used to determine a standard curve relating the number of molecules of $\mathrm{FcRn}$ to the $\mathrm{CT}$ value, which was then used to extrapolate the number of FcRn molecules in each lysate sample. The number of molecules per ng RNA (20-50 ng depending on concentration) was determined based upon the amount of cDNA. Absolute quantification of cyno FcRn was not possible because only rhesus FcRn was available for hybridization.

\section{FcRn Cellular Localization and mAb Transcytosis in Human Intestinal Cells}

These experiments were designed to determine FcRn expression and role of surface versus intracellular FcRn binding to $\mathrm{mAb}$ transcytosis in an endogenous FcRn expressing caco-2 cell line derived from colorectal adenocarcinomas.

Three methods were used to determine FcRn expression in caco-2 cells grown to confluence in transwells for 14-21 days. For flow cytometry, acutase dissociated cells were centrifuged (a) 1,800 rpm for $7 \mathrm{~min}$ at $4^{\circ} \mathrm{C}$, washed and incubated $\left(1 \times 10^{6}\right.$ cells/well in $50 \mu \mathrm{l}$ at $4^{\circ} \mathrm{C}$ for $45 \mathrm{~min}$ ) in rat anti-human FcRn polyclonal alone, or in the presence of unlabelled FcRn (50 $\mu \mathrm{g} / \mathrm{ml})$, followed by a secondary antibody $(7.5 \mu \mathrm{g} / \mathrm{ml})$. Controls included omission of the primary antibody and isotype control (rat IgG $50 \mu \mathrm{g} / \mathrm{ml}$ ). Cells were stained with near-infra-red live/dead dye $0.25 \mu \mathrm{l}$ in $50 \mu \mathrm{l}$ of PBS (Invitrogen). Plates were spun $\left(1,300 \mathrm{rpm}\right.$ for $3 \mathrm{~min}$ at $4^{\circ} \mathrm{C}$ ) and samples resuspended in $400 \mu \mathrm{l}$ of FACS buffer and run on the LSR Fortessa. For Western blot, FcRn expression in whole cell caco-2 lysates was determined in reduced $20 \mu \mathrm{l}$ samples containing equivalent protein $(\sim 15 \mu \mathrm{g})$ loaded per lane. These were run on 4-12 SDS-PAGE, blotted onto nitrocellulose membrane, and incubated in primary rabbit anti FcRn (M255; Santa Cruz, CA. 1 h at 1:300) then donkey anti rabbit 680 (Licor 1:3000). For FcRn immunofluorescence, cells were fixed in situ in 4\% paraformaldehyde and permeabilized with
$0.5 \%$ Triton X-100. After addition of Image-iT® FX signal enhancer (Invitrogen; Carlsbad, CA), cells were treated with 1X Blocking Buffer (Sigma-Aldrich; St. Louis, MO) before exposure to rat anti-human FcRn. Immunoreactivity to primary antibody was detected with a FITC-conjugated donkey anti-rat IgG secondary antibody (Jackson Immunoresearch, West Grove, PA). Prolong GOLD antifade with DAPI (Invitrogen) was added to wells prior to image capture using a Nikon SMZ-1500 fluorescence dissecting microscope.

The cellular location of mAb was determined after incubation of caco-2 cells in either FcRn-mAb binding $(p \mathrm{H} 6.0$ or FcRn binding anti-RSV WT or N435A) or non-binding ( $p \mathrm{H} 7.4$ or anti-RSV H435A) conditions. For quantification of $\mathrm{mAb}$ binding affinity on the cell surface, caco- 2 cells $\left(1 \times 10^{4}\right.$ or $2.5 \times 10^{4}$ cells per well for 2 h@ $@$ RT) were allowed to attach to the plate surface of MSD High Bind plates MSD; Rockville, MD). Plates were then blocked with 20\% FBS (Life Technologies) and $0.18 \%$ Sodium Azide (15 min RT) and washed once with DPBS at $p \mathrm{H} 6.0$ before incubation with FcRn-binding variants (anti-RSV N434A or anti-RSV $\mathrm{H} 435 \mathrm{~A}$ at $p \mathrm{H} 6.0 ; 90 \mathrm{~min}$ at $37^{\circ} \mathrm{C}$ ). This was followed by incubation with ruthenium-labeled goat anti-human IgG $\mathrm{F}\left(\mathrm{ab}^{\prime}\right) 2(1 \mu \mathrm{g} / \mathrm{ml}$ in DPBS at $p \mathrm{H} 6.0$ for $1 \mathrm{~h} \mathrm{RT})$ and then Tris-based Read Buffer $\mathrm{T}$ without surfactant was added to wells immediately before measuring RLU, as described previously. Background subtracted RLU's were used to calculate mAb binding $\mathrm{IC}_{50}$ by variable slope non-linear regression (GraphPad Prism 5.0).

For detection of $\mathrm{mAb}$ in cell lysates from caco- 2 monolayers grown in transwells, mAb (anti-RSV WT or H435A) were incubated on apical side for $90 \mathrm{~min}$ at $p \mathrm{H}$ 6.0, then thoroughly rinsed ( 3 times in cold PBS) and cells scraped into $250 \mathrm{ml}$ M-per lysis buffer with protease inhibitors. Surface FcRn-dependent apical-to-basolateral transcytosis was tested in caco-2 monolayers grown in transwells by apical incubation of cells of WT or $\mathrm{H} 435 \mathrm{~A}$ mAb at $p \mathrm{H} 6.0$ or 7.4 for 90 mins. The mAb concentration in cell lysates and on the basolateral side were determined by MSD format and back-calculation from standard curves $(0.005-500 \mathrm{ng} / \mathrm{mL})$, as described in previous section.

\section{RESULTS}

\section{FcRn Expression and mAb Transcytosis in Human Donor Intestines}

To determine regional intestinal differences in $\mathrm{mAb}$ transcytosis, isolated muscle-stripped human intestinal segments ( $n=9$ per region, 3 donors) were incubated on the mucosal side with M15 (anti-growth factor with high FcRn binding affinity; 20 and $200 \mu \mathrm{g} / \mathrm{mL}$ in KRB buffer at $p \mathrm{H} 6.5$ ). This resulted in a concentration-related increase in M15 detected at 180 mins in all small intestinal regions and 
proximal colon (Fig. 1a). However, mAb concentration detected across the proximal colon tended to be slightly higher (Fig. 1a). Differences in mAb detection on the basolateral side were not due to tissue handling or permability since atenolol, a low molecular weight low permeability compound co-mixed with the mAb, had low apparent paracellular permeability that was well within acceptance criteria for the presence of an intact barrier function in these segments. FcRn protein expression in mucosal scrapings of the adjacent (non-incubated) segments was higher in the proximal colon compared to the lowest expressing region, which was the jejunum (Fig. 1b).
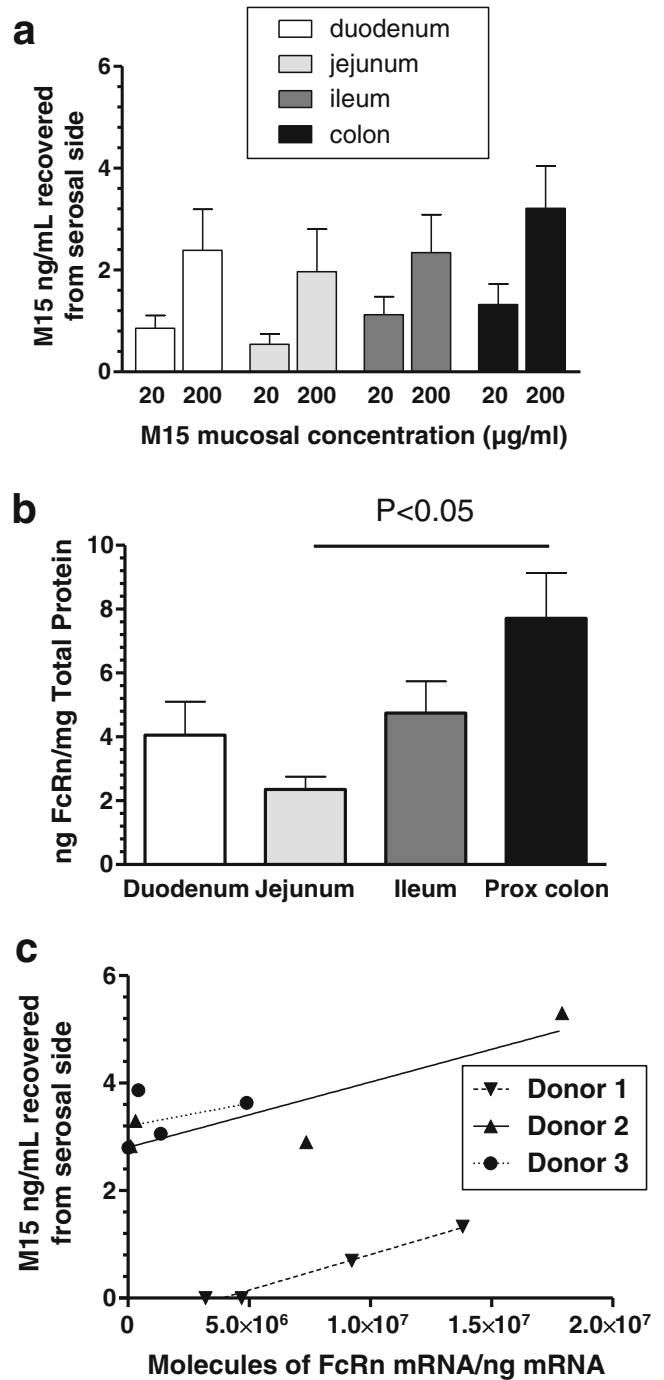

Fig. I Human donor muscle-stripped intestinal segments (three segments in each of four regions per donor for a total of $n=9 /$ region, mean \pm SEM) assessed for transcytosis and FcRn protein and mRNA expression. Segments mounted in Ussing-type flux chambers were incubated on the mucosal-side with MI5 (20 and $200 \mu \mathrm{g} / \mathrm{mL}$ ) and concentration-related low levels of fulllength $\mathrm{mAb}$ were detected on the serosal side after 180 mins (a). In adjacent intestinal mucosal scrapings (b), protein levels of FcRn (by ELISA) in proximal colon were higher than in jejunum $(P<0.05$ by ANOVA and NewmanKreuls post-test). When FcRn mRNA/total mRNA was plotted against MI5 mAb uptake for each donor (c), there was an apparent correlation.
Similar to this, the molecules of FcRn mRNA detected in the mucosa tended to be relatively higher in colon than jejunum but varied between donors. When the FCRn mRNA expressed per segment was plotted against mAb trancysosis for each donor there appeared to be a correlation (Fig. 1c), although high donor-to-donor variability was apparent.

FCRn immunoreactivity in full-thickness sections of same human donor intestines was visualized in villous enterocytes of small intestine (Fig. 2a, b; large arrowheads), as expected. Qualitatively, FcRn immunostaining was similar in colonic and small intestinal enterocytes from the same donor (Fig. 2c, d; arrowheads). Unexpectedly, intense FcRn immunoreactivity was noted in a few cells located in the small intestinal crypts and proximal colon from all donor intestines (Fig. 2a, c; small arrows). These cells will be described later in the "Results" section.

To translate the relative expression of FcRn mRNA in human intestinal mucosa into some idea of transcytosis efficiency, the absolute FcRn mRNA expression in four intestinal regions was compared in adult human, adult rat, and suckling rat pup (Fig. 3). These were selected because rat pup has high FcRn expression with high FcRn transcytosis efficiency whereas adult rat loses FcRn expression after weaning. Overall, human intestinal FcRn mRNA (Fig. 3a) showed a gradient of increasing expression from proximal to distal intestine. In the jejunum/ileum, FcRn mRNA levels were $\sim$ two-fold greater than in adult rat, and proximal colon was $\sim$ ten-fold greater (Fig. 3b). This contrasted with the rat pup intestine where the highest FcRn mRNA was in the duodenum and jejunum $(7,9)$ and was $\sim$ ten-fold greater than human proximal colon (Fig. 3c). Consistent with the higher duodenal mRNA expression in rat pup, higher serum mAb levels were obtained in isoflurane-anesthetized 2-week-old rat pups after direct duodenal dosing, compared to distal small intestine or proximal colon administration (Fig. 3d). Thus, the regional efficiency of $\mathrm{mAb}$ uptake reflected the decreasing gradient of FcRn mRNA expression in rat pups. Overall, since the levels of FcRn mRNA found in human were above adult rat intestine (no FcRn mediated transport) and an increasing proximal-distal gradient in FcRn expression levels was noted, mAb systemic uptake after regional intestinal delivery was subsequently evaluated in adult primates.

\section{FcRn Expression and In Vivo mAb Intestinal Uptake to Serum in Cynomolgus}

In vivo experiments were performed in nine cynomolgus monkeys that were dosed over a 7 month period (Table II). Monkeys were dosed by oral gavage, proximal intestinal administration by videogastroendoscopy, or by laparotomy followed by direct surgical infusion through the intestinal wall into the small intestine and proximal colon. Seven monkeys had a repeat administration of anti-growth factor mAb. In 
Fig. 2 FcRn immunoreactivity in fixed and paraffin-imbedded $5 \mu \mathrm{m}$ sections of donor ileum (a) and colon (c) confirms the ELISA data shown in Fig. Ib. FcRnimmunostaining in intestinal enterocytes (arrowheads) was above background staining observed in adjacent control rat lgG stained sections $(\mathbf{b}, \mathbf{d})$.

Unexpectedly, intense FcRn immunostaining was visualized in a few cells within the small intestinal crypts and proximal colon, which were not observed in controls (small arrows).
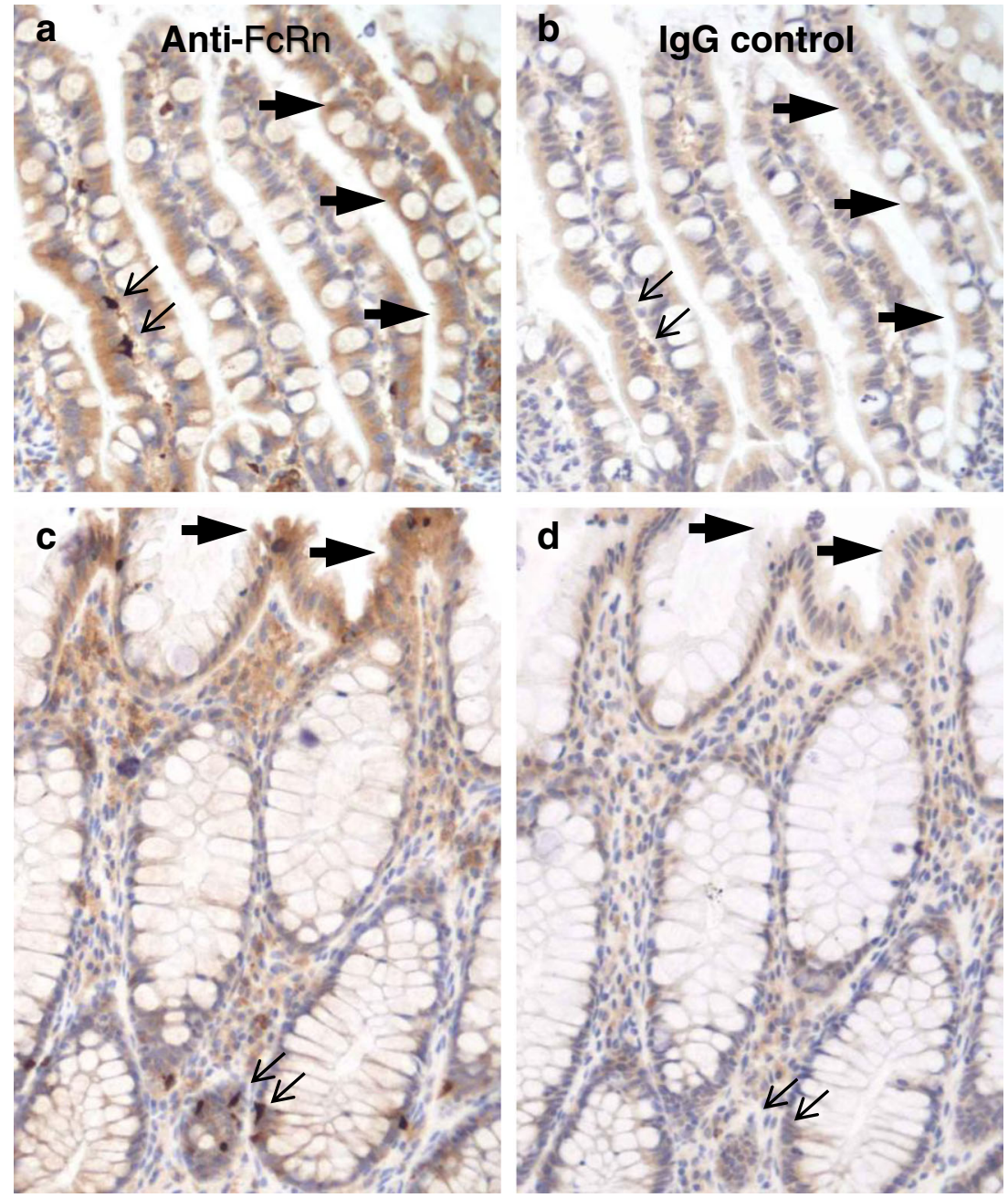

cases where there was a third mAb administration, anti-RSV was dosed instead (Table II) to reduce the likelihood of interference in $\mathrm{mAb}$ detection because of potential monkey antiidiotype antibodies to anti-growth factor in circulation.

The initial videogastroscopy dosing into duodenum/ jejunum (1-2 mg/kg; $n=4)$ resulted in low but detectable serum levels of anti-growth factor mAb in two monkeys as early as 90 mins later (diamonds, Fig. 4e). In monkeys where serum was collected up to $48 \mathrm{~h}$ after dosing, mAb levels peaked at 24 hrs (circles, Fig. 4e). In two different monkeys, videogastroscopy delivery into the duodenum/proximal jejunum with higher dose ( $5 \mathrm{mg} / \mathrm{kg} \mathrm{M} 15, n=2)$, did not result in higher serum levels (Table II). Oral gavage into the stomach $(2.5 \mathrm{mg} / \mathrm{kg}, n=3)$ resulted in no detectable serum levels (e.g. at $24 \mathrm{~h}$; Table II) up to $96 \mathrm{hrs}$. In these three monkeys subsequent IV administration of the M15 (FcRn higher binding affinity anti-growth factor $\mathrm{mAb} 0.05 \mathrm{mg} / \mathrm{kg}$ ) was performed to determine circulating half-life (Table II). The individual serum levels (total of eight time points from 1.5 to $504 \mathrm{~h}$ in Table II) are reported for all three monkeys. The individual concentration-time profile (1.5-504 h post dosing) was analyzed using non-compartmental analysis by Winnonlin (v5.2), which resulted in a circulating half-life $\sim 14$ days. Therefore, the serum concentration up to at least $48 \mathrm{~h}$ after intestinal administration should reflect intestinal uptake and not be confounded by loss of $\mathrm{mAb}$ from circulation.

A dose of $\mathrm{mAb}$ acutely ( $5 \mathrm{mg} / \mathrm{kg}, n=2$ ) into five regions throughout the small intestine and proximal colon (panintestinal delivery), resulted in the higher detectable $\mathrm{mAb}$ serum levels at 90 mins (3 and $14 \mathrm{ng} / \mathrm{ml}$ ) than proximal intestine administration. FcRn immunostaining was noted in enterocytes from a mucosal biopsy from duodenum/jejunum transition (Fig. 4a), and post-mortem full-thickness proximal colon (Fig. 4c) of the same monkey. However, small intestinal FcRn mucosal distribution tended to be patchy (arrows in Fig. 4a, b), whereas colonic staining was more evenly distributed and diffuse (arrows in Fig. 4c, d). The high background and histological damage in the colon segment (Fig. 4d) was due to a delay in fixation after removal in the surgical suite, but differential intensity of enterocyte FCRn-staining and control was still evident. Together with the initial small intestinal dosing results, the FcRn immunostaining suggested that 
Fig. 3 FcRn mRNA expression quantified to total mRNA in human donor mucosa (a) where $n=3$; adult rat mucosa (b) where $n=5$, and suckling rat pup full-thickness sections (c) where $n=4$ (raw data were log transformed since underlying assumptions of equal variance and normal distribution shape were more tenable). (d) In suckling rat pups $(n=6), \mathrm{mAb}$ serum levels were greater after administration of MI5 into the proximal than to the distal small intestine and showed a functional proximal- distal gradient paralleling FcRn mRNA expression. $P<0.05$ by I-way ANOVA and Bonferroni's post-tests. a

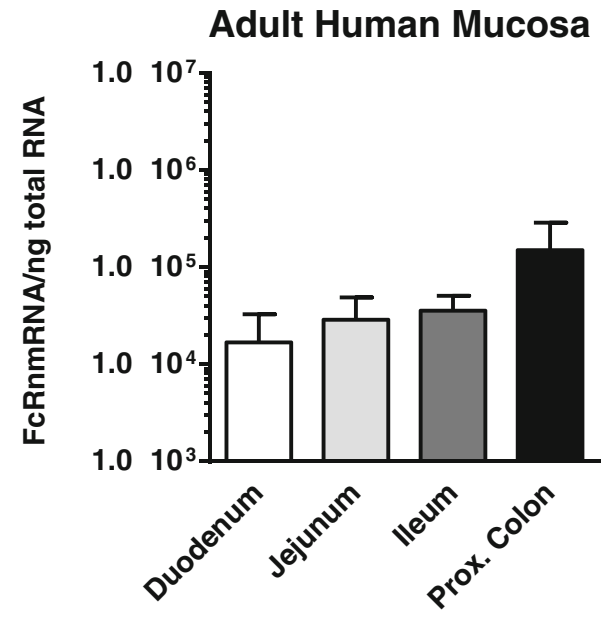

C

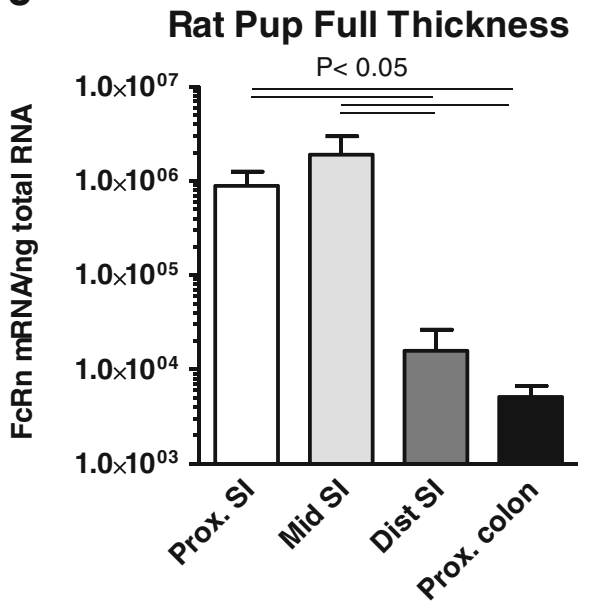

b

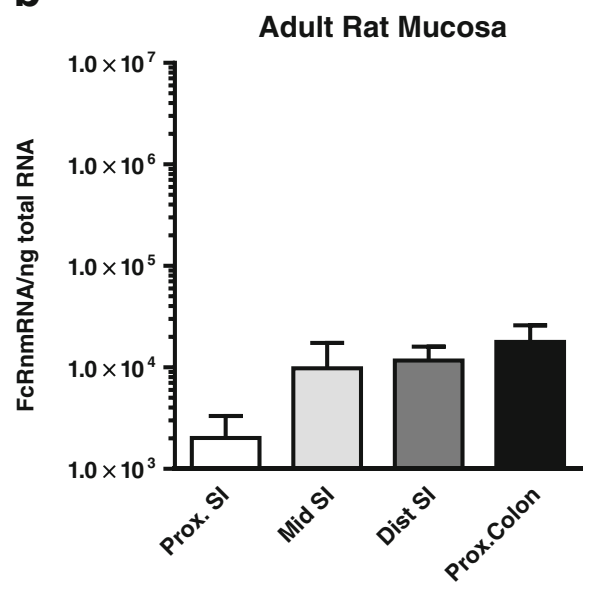

d

Rat Pup mAb Serum levels

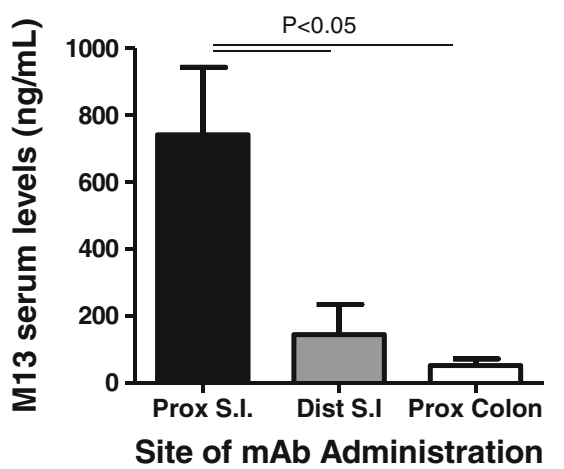

the distal small intestine or proximal colon might be where most intact $\mathrm{mAb}$ uptake was occurring.

We tested this directly by dosing WT mAb and H435A variant into distal ileum/proximal colon after laparotomy in five monkeys, and the individual mAb concentration in serum and gastrointestinal fluid are illustrated (Fig. 4f). High individual variability was noted in the concentration of full-length $\mathrm{mAb}$ in distal small intestine and proximal colon fluid (Fig. 4f), and very low intestinal $\mathrm{mAb}$ concentrations in two monkeys (one in each group) was associated with the lowest serum levels. Figure $4 \mathrm{f}$ illustrates that, compared to previous intestinal dosing, the highest detectable serum levels were achieved in 2 of 3 monkeys dosed with B21M WT $(124 \pm 104 \mathrm{ng} / \mathrm{mL}$; $2 \mathrm{mg} / \mathrm{kg}, n=3$ mean $\pm \mathrm{SEM}$ ) and 1 of 2 monkeys dosed with the non-FcRn binding variant H435A $(48 \pm 48 \mathrm{ng} / \mathrm{mL}$ mean $\pm \mathrm{SEM} ; 2 \mathrm{mg} / \mathrm{kg}, n=2)$. However, there was no statistically significant difference between the serum uptake of WT and H435A variant at 90 min post-dosing. Serum fractional uptake was calculated based for the predicted blood volume by gender and weight of cynomolgus macaques (29). Based on monkey weight taken just prior to dosing, the fractional uptake into serum of the dose administered into intestines was $0.32 \%$ and $0.15 \%$, respectively. Samples of jugular blood that were taken close to the entry of the thoracic duct resulted in slighly higher levels of $\mathrm{mAb}$ than femoral bleeds for each monkey (Fig. 4f), suggesting that uptake through the lymphatic system was occuring in these animals.

\section{In Vitro FcRn Surface Expression and Transcytosis in Human Intestinal Enterocytes}

The in vivo data were consistent with distal small intestine/ colon uptake of $\mathrm{mAb}$ but inconclusive as to whether $\mathrm{FcRn}$ binding influences $\mathrm{mAb}$ intestinal uptake in primates, despite the presence of $\mathrm{FcRn}$ in enterocytes. We reasoned that if $\mathrm{mAb}$ on apical surface was internalized by pinocytosis rather than being $\mathrm{FcRn}$-dependent, then this would limit $\mathrm{mAb}$ uptake in vivo. To test this, several different experimental approaches in caco- 2 cells were used to determine FcRn cell surface engagement and $\mathrm{mAb}$ transcytosis in vitro (Fig. 5). Western blots of caco-2 cell lysates confirmed intense anti-FcRn bands at a molecular weight $\sim 42 \mathrm{kD}$ similar to recombinant human 

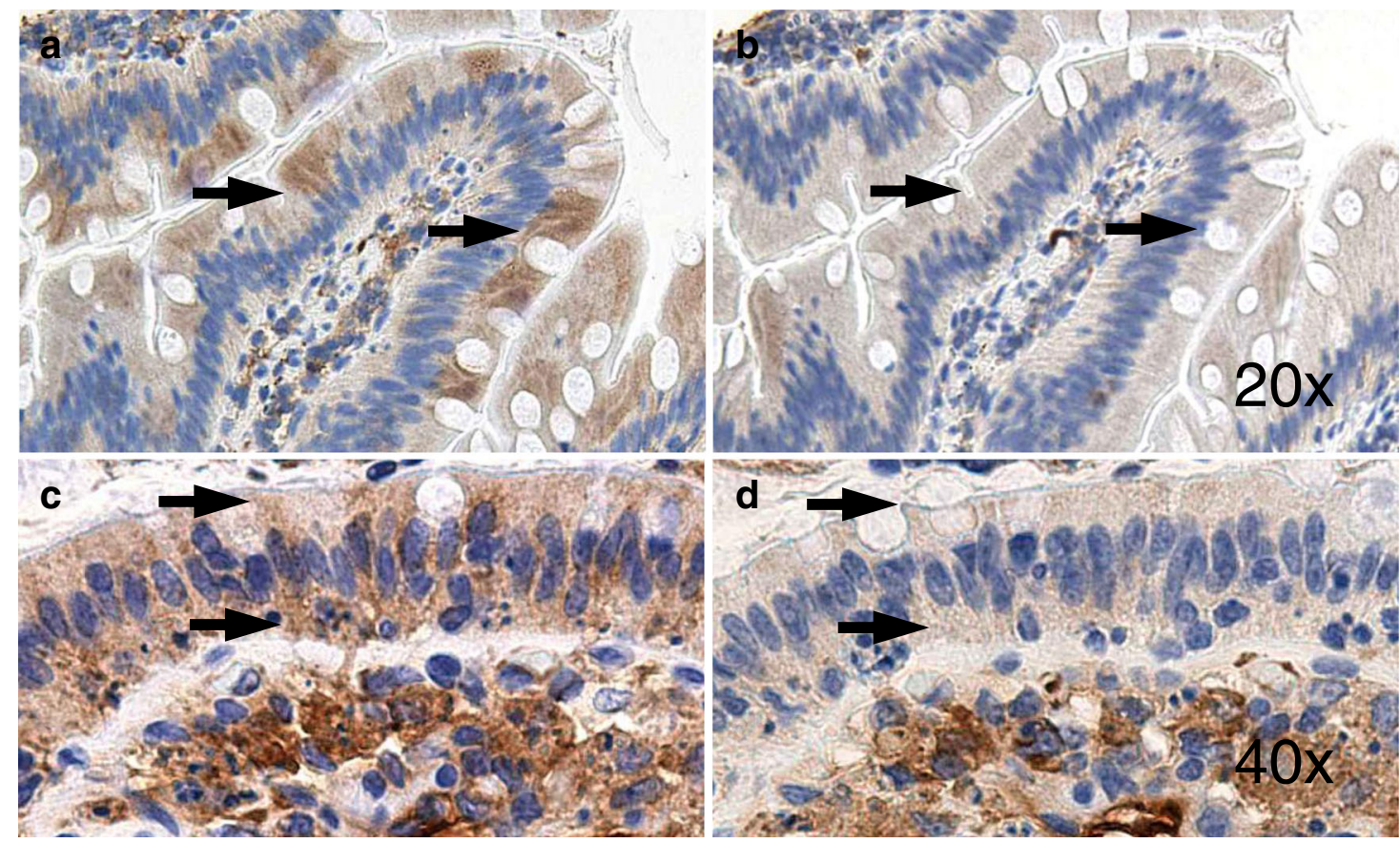

e

\section{f}
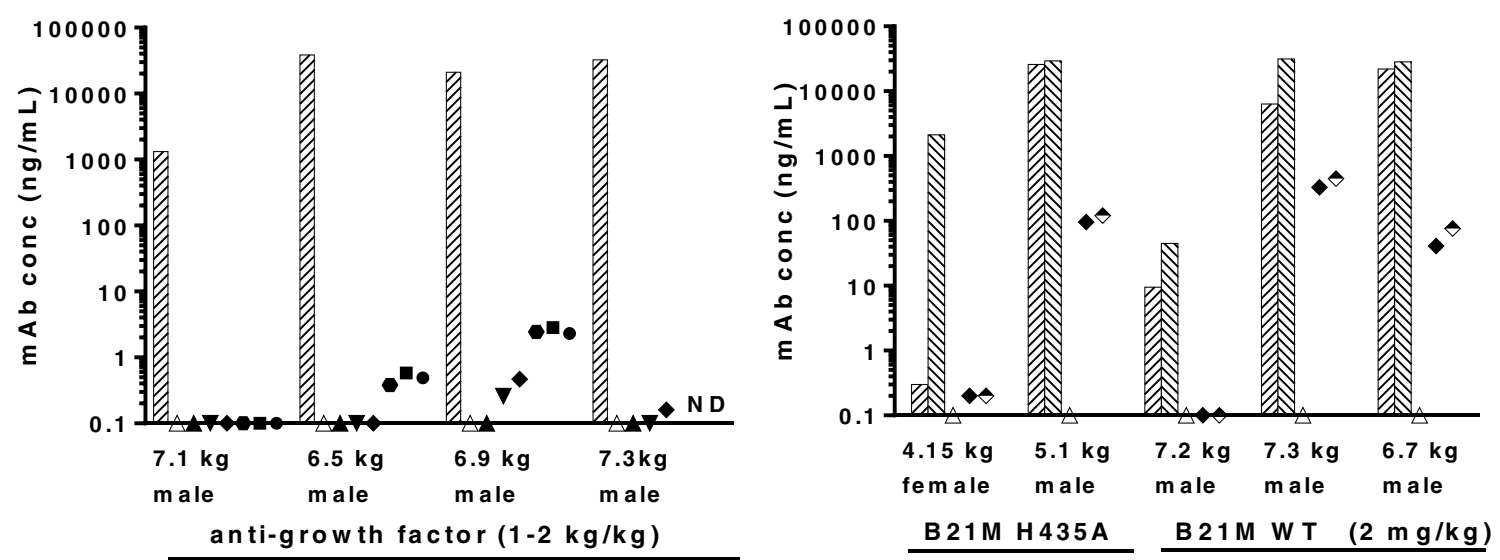

\begin{tabular}{|lll|}
\hline VIIA Prox. SI fluid $90 \mathrm{~m}$ in & $\bullet$ & serum $90 \mathrm{~m}$ in \\
$\triangle$ Pre-dose serum & - serum $4 \mathrm{~h}$ \\
$\boldsymbol{\Delta}$ serum $5 \mathrm{~min}$ & - serum $24 \mathrm{~h}$ \\
$\boldsymbol{\nabla}$ serum $45 \mathrm{~min}$ & - serum $48 \mathrm{~h}$ \\
\hline
\end{tabular}

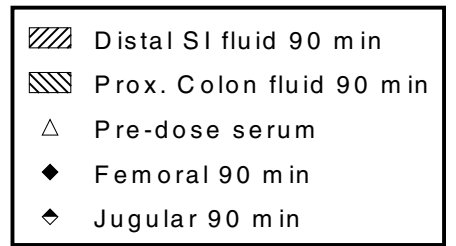

Fig. 4 Cynomolgus monkey intestine FcRn immunostaining and mAb levels after dosing. Duodenal/jejunal mucosal biopsy illustrated patchy FcRn immunostaining in villous enterocytes (a, arrowheads), which was not observed in adjacent control rat lgG section (b). In the same monkey, full-thickness proximal colon has FcRn-immunostaining evenly distributed throughout (c, arrowheads). Artifactual and non-specific staining (d) is due to post-mortem tissue handling. In 3 out of 4 isoflurane-anesthetized cynomolgus anti-growth factor $\mathrm{mAb}$ dosed into the proximal small intestine $(\mathrm{I}-2 \mathrm{mg} / \mathrm{kg})$, resulted in low femoral vein serum levels postdosing at 90 mins and up to $48 \mathrm{~h}(\mathbf{e})$. Dosing mAb acutely into the ileum and proximal colon ( $2 \mathrm{mg} / \mathrm{kg}$ anti-RSV H435A, $n=2$; and WT, $n=3$ ) resulted in much higher femoral vein serum levels at 90 mins in 3 out of 5 monkeys (f). In these 3 monkeys, mAb concentrations were slightly higher from jugular vein (taken near thoracic duct). Very low intestinal fluid mAb concentrations in two monkeys were associated with very low serum mAb levels. ND =Not Done.

FcRn, as expected (11)(data not shown). This was supported by intense cytoplasmic $\mathrm{F}_{\mathrm{C} n} \mathrm{immunofluorescence,} \mathrm{although}$ heterogeneity of FcRn-expressing and non-FcRn-expressing cell populations was noted (Fig. 5a). By flow cytometry, surface FcRn expression occurred in $62 \%$ of the total population of dissociated cells (Fig. 5b). The $\%$ of population is shown (Fig. 5b) rather than Mean Fluorescence Units (MFI) because of the apparent FcRn-expressing heterogeneity of caco-2 cells. Cell surface mAb binding with an $\mathrm{IC}_{50}$ of $1.5 \mu \mathrm{g} / \mathrm{ml}$ was obtained for a high affinity FcRn-binding mAb variant, with 
a

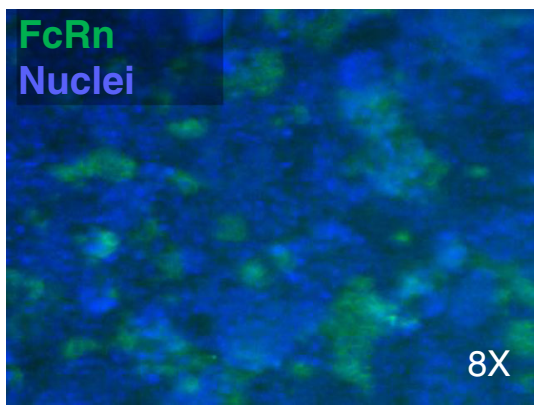

C

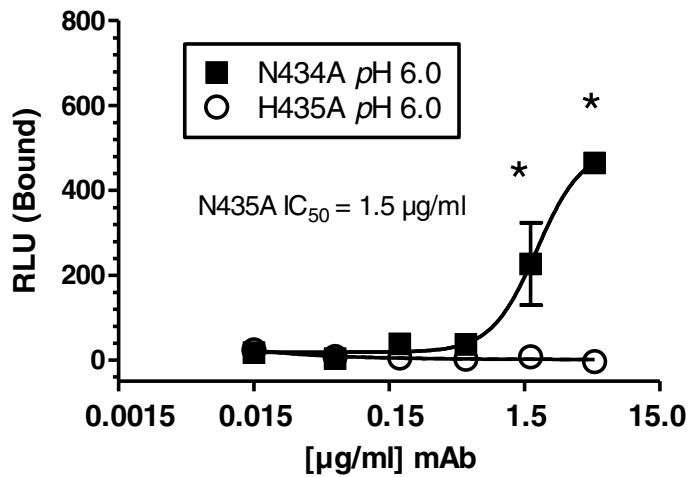

b

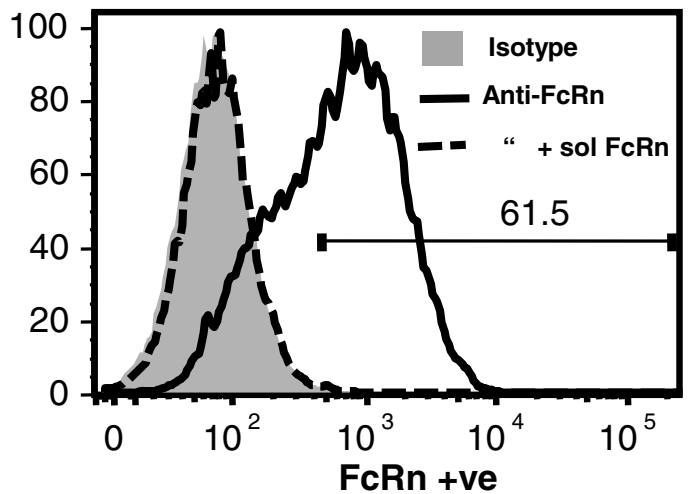

d

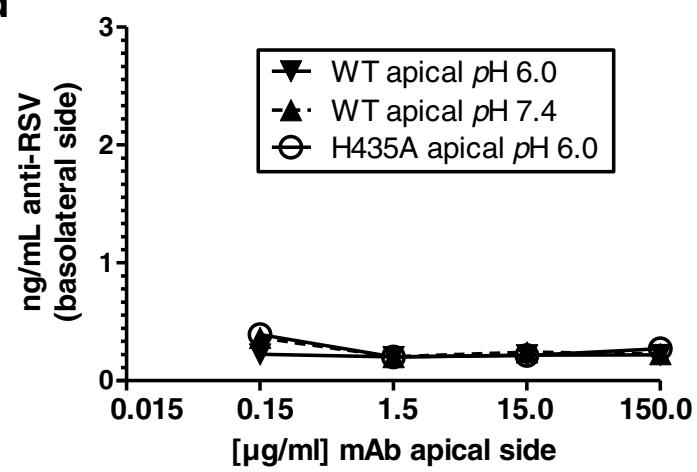

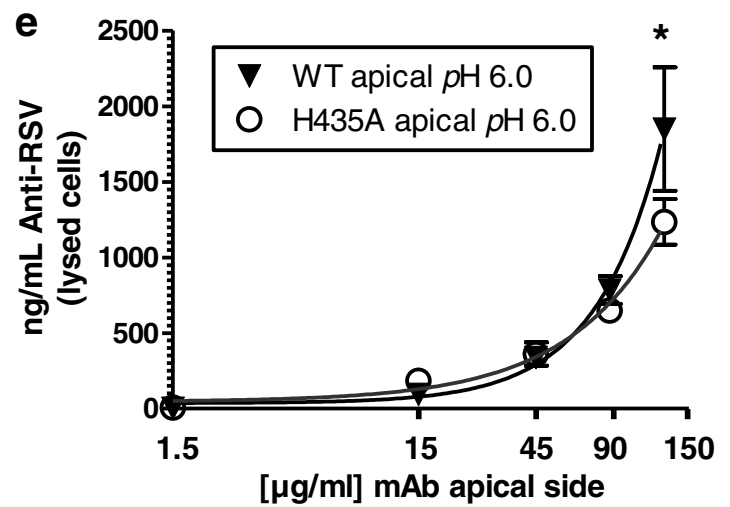

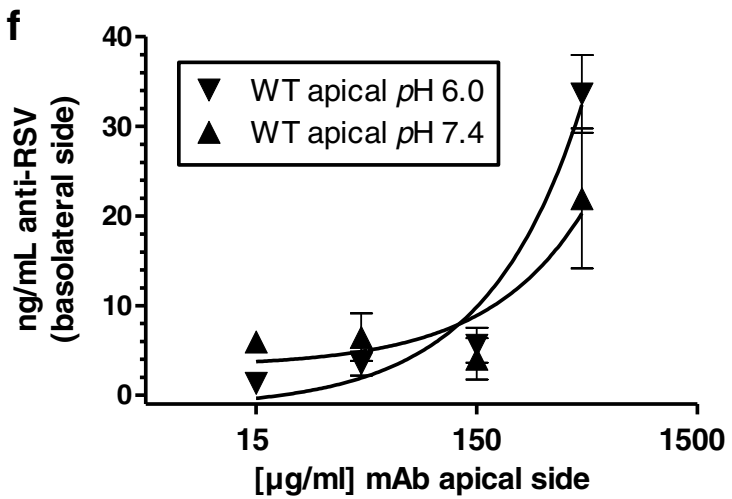

Fig. $5 \mathrm{FcRn}$ expression and mAb localization in caco-2 cells. (a) Immunofluorescence of FcRn and nuclear DAPI illustrates intense intracellular FcRn in heterogeneous cells. (b) By flow cytometry, 60\% of dissociated caco-2 cells had cell surface FcRn expression that was competitively abolished using an equal concentration of soluble unlabeled $\mathrm{FcRn}$. (c) A detectable signal for surface binding of an FcRn-binding affinity mAb ( N434A $0.000 \mathrm{I}-5.0 \mu \mathrm{g} / \mathrm{ml}$ ) in dissociated caco-2 cell resulted in an $\mathrm{IC}_{50}=1.5 \mu \mathrm{g} / \mathrm{ml}(0.0 \mathrm{I} \mu \mathrm{M})$. A non- $\mathrm{FcRn}$ binding $\mathrm{mAb}(\mathrm{H} 435 \mathrm{~A})$ had no measurable surface binding $(n=3$ per group) $(\mathbf{d})$ In polarized caco-2 cell monolayers apical to basolateral mAb transcytosis did not occur after incubation at apical concentrations close to the surface $\mathrm{FcRn}_{\mathrm{c}} \mathrm{binding} I \mathrm{C}_{50}(\mathrm{I} .5 \mu \mathrm{g} /$ $\mathrm{ml}$ ) for either WTor H435A ( $n=3$ per group). (e) In polarized caco-2 cell monolayers grown in transwells, apical incubation of mAb concentrations well above the surface $\mathrm{FcRn-binding} I \mathrm{C}_{50}$ resulted in intracellular detection of more WT than non-FcRn binding variant in lysed cells at the highest concentration ( $n=4$ per group; $P<0.05$ by 2 -way ANOVA and Bonferroni's post-test). (f) Similar apical-to-basolateral transcytosis of WT by caco-2 cell monolayers grown in transwells incubated at higher WT concentrations at either apical $\mathrm{pH} 6.0$ or $\mathrm{pH} 7.4$ ( $n=6$ per group).

a low signal (RLU) that suggests a low FcRn expression on the cell surface (Fig. 5c). Negligable specific binding was detected on the cell surface for $\mathrm{H} 435 \mathrm{~A}$, a non-FcRn binding variant (Fig. 5c).

It should be noted that flow cytometry and cell surface binding were performed on dissociated (ie not polarized) cells. In polarized caco-2 cell monolayers, apical incubation of $\mathrm{mAb}$ at concentrations around the surface $\mathrm{FcRn}$ binding $\mathrm{IC}_{50}$, failed to demonstrate surface $\mathrm{mAb}$ transcytosis after 90 mins (Fig. 5d). However, apical incubation of mAb at 100 fold greater concentration than the surface $\mathrm{F}_{\mathrm{C}} \mathrm{Rn}$-binding $\mathrm{IC}_{50}$, resulted in more WT than non-FcRn binding variant detected in lysed cells (Fig. 5e). Thus, mAb was internalized at this higher concentration and endosomal IgG-FcRn binding occurred. Apical-to-basoloateral transcytosis of WT by caco-2 cell monolayers was similar up to $450 \mu \mathrm{g} / \mathrm{ml}$ whether apical incubations 
were done at $p \mathrm{H} 6.0$ or $p \mathrm{H} \mathrm{7.4.} \mathrm{All} \mathrm{these} \mathrm{data} \mathrm{suggest} \mathrm{that}$ apical surface $F_{C} R n$ expression is low and surface FCRn-IgG binding was inconsequential to overall transcytosis. Based on these findings, mAb present in the intestinal lumen that had enhanced affinity to FcRn would not be expected to have faster entry into endocytotic pits in a receptor-mediated fashion.

\section{Novel Observation of FcRn Immunostaining in Primate EnteroEndocrine Cells}

Intense FcRn immunostaining in human small intestine crypt cells was visualized in banked human intestinal samples. Because this had not been reported previously we compared the FcRn localization by the in-house anti-FcRn to a commercially available anti-FcRn (H-274, Santa Cruz, CA) in adjacent sections (Fig. 6a, b). Sections were 5 um apart which resulted in some variation in cell presence and visibility between sections; however, two apparent matches of commercial and in-house antiFcRn stained cells were noted in this example (Fig. 6a, b arrows). High background staining in the case of the purchased antiFcRn hampered detection of specific FcRn immunostaining.

Due to the FcRn localization in crypt cells and their morphological appearance, human small intestinal tissue was thinsectioned for FcRn colocalization studies using chromagranin A (Fig. 6c,d), Glucagon-Like Peptide (GLP)-1 (Fig. 6e,f), and GLP2 (Fig. 6g,h) immunostaining in the adjacent section. Overall, the prevalence of FcRn-immunoreactive cells was lower than chromagranin A stained cells, which suggested that FcRn was colocalized sub-populations of enteroendocrine cells (Fig. 6c,d arrows). FcRn-immunostaining in cells overlapped more extensively with GLP-1 and GLP-2 immunoreactive cells. However, EE hormones other than just GLP1 and GLP-2 were likely to be colocalized with FcRn throughout the small intestine, colon and stomach. For example, gastrin, cholecystokinin (CCK) immunostained cells were extensively colocalized with FcRn in the stomach (data not shown). Comprehensive immunoflourescence colocalization would be necessary to determine the prevalence and identity enteroendocrine cells that expressed FcRn.

To determine the prevalence of FcRn-immunostaining in cells from a variety of sources, colon samples of human neonatal $(n=3)$, cynomolgus $(n=2)$ and mouse $(n=4)$ were compared. In general, neonatal colon crypt cells had a greater frequency and intensity of FcRn staining than adult, as illustrated in the example (Fig. 7a, b). Cynomolgus colon had a low prevalance, but similar localization of FcRn immunostained cells (Fig 7c, d). However, no FcRn specific -immunoreactivity was apparent in C57b6 mice intestine compared to rat IgG negative control, as illustrated in proximal colon (Fig. 7e, f).

\section{DISCUSSION}

This study addresses how previous evidence for FcRnmediated IgG transcytosis in epithelial cells $(12,13,30)$ might translate into mAb oral bioavailability in primates. Our novel findings are that, in adult human intestine, there is an
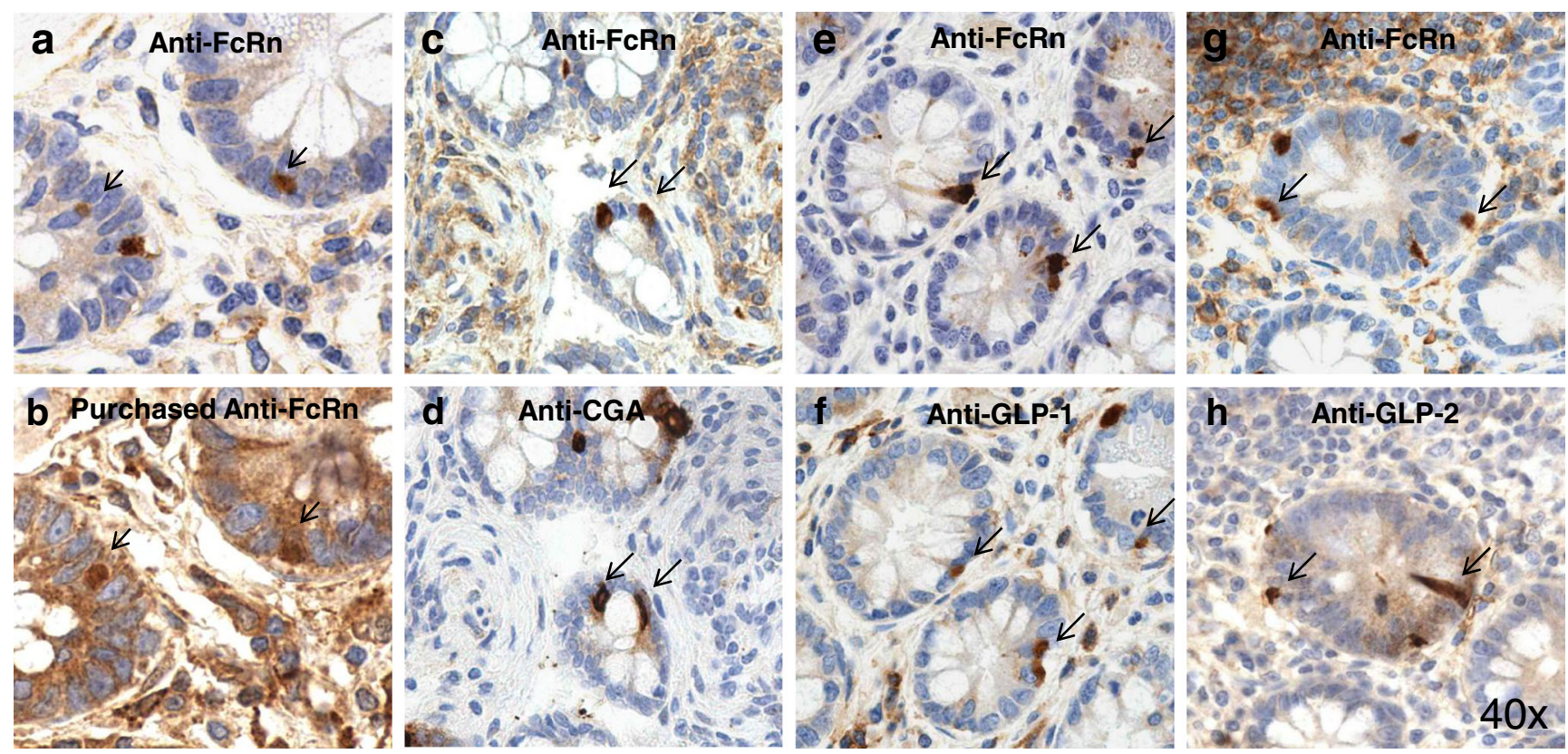

Fig. 6 Crypt cell FcRn immunostaining in human small intestine using in house anti-FcRn (top row) was colocalized (arrows) with commercially available anti-FcRn (b), chromagranin A (d), GLP-I (f), and GLP-2 (h) immunostaining in the adjacent section that were $5 \mu \mathrm{m}$ apart. A high background-signal using anti-FcRn (H274, Santa Cruz; b) hampered detection of specific FcRn immunostained cells, though two apparent matches to in-house anti-FcRn stained cells are indicated (a, b arrows). FcRn-immunoreactive cells (c) were less prevalent than chromagranin A stained cells (e), with some matches that suggest a colocalized sub-population (arrows). FcRn-immunostaining (e, g) overlaps extensively in GLP-I (f) and GLP-2 (h) immunoreactive cells. 


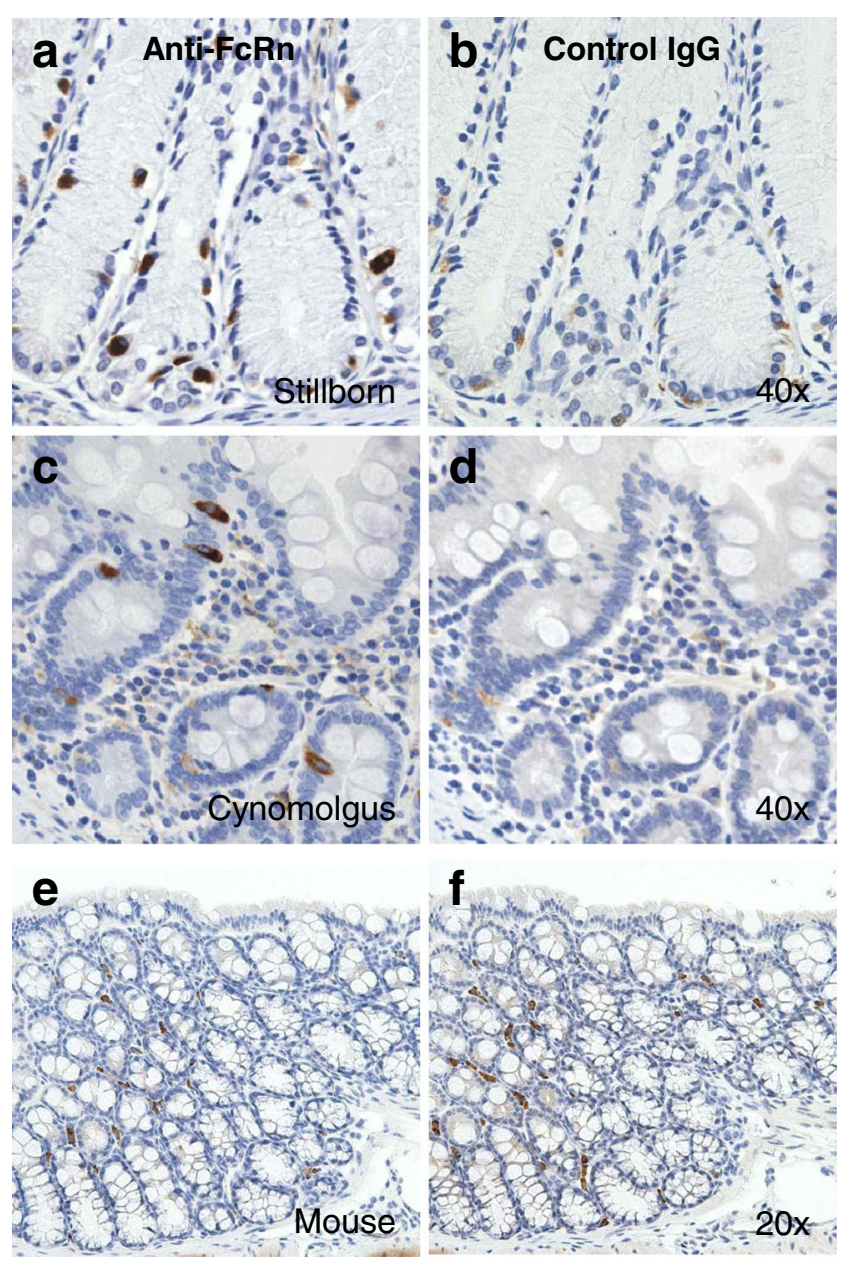

Fig. 7 Crypt cell FcRn immunostaining and adjacent control rat $\lg G$ in banked colon from stillborn (a, b), cynomolgus monkey $(\mathbf{c}, \mathbf{d})$ and C57b6 mice $(\mathbf{e}, \mathbf{f})$. The intensity numbers of $\mathrm{FcRn}$ immunostained cells were the highest in neonatal human. Adult cynomolgus was similar to adult human. No FcRn reactivity was apparent in C57b6 mice throughout the intestine compared to rat $\lg G$ negative control and illustrated in proximal colon.

increasing proximal-distal gradient of $\mathrm{FcRn}$ expression, with highest FcRn expression in the proximal colon. Consistent with this, greater levels of mAb transfer across the intestinal wall were noted in both isolated human intestine proximal colon and after acute ileum/proximal colon administration in adult cynomolgus in viwo. However the fractional uptake of full-length $\mathrm{mAb}(\sim 0.3 \%)$ was still relatively low. In addition, variability in intestinal $\mathrm{mAb}$ proteolysis contributed to variable serum levels resulting in no group differences in serum levels of WT mAb compared to non-FcRn binding affinity $\mathrm{mAb}$. These points will be discussed in the context of the known literature on intestinal $\mathrm{FcRn}$ with respect to the likelihood of oral delivery of $\mathrm{mAb}$ by this mechanism.

Previously, no difference in the regional expression of $\mathrm{F}_{\mathrm{c}} \mathrm{Rn}$ in human fetal intestine was noted by western blot (11), whereas a decreasing $\mathrm{FcRn}$ proximal-distal has been reported by several groups in neonatal rat pups $(7,9)$. This present study is the first to demonstrate an increasing FCRn proximal-distal gradient of expression in adult human intestine, in contrast to neonatal rodents. However, it is hard to translate expression levels into functionality. Therefore, we compared FcRn $\mathrm{mRNA} / \mathrm{ng}$ total RNA expression using probes $100 \mathrm{bp}$ in length estimate total cDNA across species. This approximated the $\mathrm{FcRn}$ expression in human proximal colon to be $\sim 10$ fold lower than neonatal rat pup duodenum and $\sim 10$ fold higher than adult rat intestine. Since adult rat intestine $(8,9)$ did not express sufficient intestinal $\mathrm{FcRn}$ for $\mathrm{mAb}$ transport, this could represent a 'floor' of mRNA that does not translate into protein function. The fact that human proximal colon $\mathrm{F}_{\mathrm{c}} \mathrm{Rn}$ mRNA expression is above that floor level and only 10 fold lower that neonatal rat duodenum where IgG is actively transported $(8,9)$ suggests that $\mathrm{FcRn}$ mediated transport might be expected.

The $0.3 \%$ fractional mAb uptake obtained from adult primate ileum/colon is much less than the $\sim 20 \%$ fractional uptake from duodenum of suckling rat pups $(7,9)$, which is consistent with the latter being a mechanistic model of $\mathrm{FcRn}$ transcytosis but not predictive of oral biovailability in adult primate. The $0.3 \%$ fractional uptake from ileum/colon delivery is markedly greater than uptake from the primate upper gastrointestinal tract, and had not been reported previously. Even though uptake is low it is possible that, with a long enough circulating half-life and a sufficiently potent $\mathrm{mAb}$, therapeutic levels could be achieved after repeated (daily) dosing with a mAb formulated for specific ileo-colonic release from an enteric coated capsule. One issue in the monkey intestinal dosing study was the high variability in systemic uptake, which was a reflection of the extent of $\mathrm{mAb}$ proteolysis in the intestinal contents. In two monkeys, one dosed with WT and one dosed with $\mathrm{H} 435 \mathrm{~A}$, there were very low mAb levels detected in the luminal contents, and in both individuals extremely low serum levels were detected. This means that additional engineering or formulation to protect the $\mathrm{mAb}$ from proteolysis should improve bioavailability. That additional optimization is needed is to be expected, similar to a report where inhaled bioavailability of a bivalent erythropoietin-Fc fusion molecule in adult primates was still relatively low, maybe due to steric hindrance, compared to a 'monomeric' erythropoietin-Fc fusion protein (18). Optimization of biophysical properties for colonic site-specific delivery could enhance $\mathrm{mAb}$ oral bioavailability.

Ninety minutes after dosing into the ileum/proximal colon, $\mathrm{mAb}$ levels in the jugular vein, taken near the entrance of the thoracic duct, were slightly higher in each monkey compared the systemic circulation. This is noteworthy because large molecules within the lamina propria interstitium enter the lymphatic lacteals through an incomplete basal lamina and lack of tight junctions (31) and empty via the thoracic duct into junction of the left subclavian and jugular vein. We previously demonstrated in suckling rat pups, that mAb enters the 
circulation via the lymphatics rather than mesenteric drainage into the hepatic portal vein (9), thus avoiding a 'first pass' effect. The present data in monkeys suggest that the absorption of mAb into the circulation occurs through the same route and also mitigates concern that the serum levels detected were due to surgical damage.

In spite of an improvement in uptake $(0.3 \%)$ after acute ileum/proximal colon delivery of WT mAb compared to oral gavage $(0 \%)$, it was inconclusive whether $\mathrm{FcRn}$ binding affinity affected transcytosis in vivo. In enterocytes, $\mathrm{FcRn}_{\mathrm{R}}$ is primarily located in the endosomes $(4,11)$ but there are a number of reports that FCRn is also located on the apical surface in human intestinal epithelial cell lines $(12,22)$ and as well as receptors on the brush borders of neonatal enterocytes (4). Therefore, we designed pharmacological experiments using caco-2 cells in vitro to determine if apical surface FcRn expression contributed to $\mathrm{mAb}$ transcytosis, in addition to the internalization and endosomal FcRn-mAb interactions that were reported previously in caco-2 cells (32). Both flow cytometry and immunohistochemistry showed that a population of caco2 cells expressed FcRn on the cell surface. In confirmation of this FcRn surface binding affinity of WT mAb was $1.5 \mu \mathrm{g} / \mathrm{ml}$, whereas H435A had no binding affinity. However, in caco-2 cells grown in transwells, cell surface FcRn binding of IgG on the apical side around the $\mathrm{IC}_{50}$ concentrations did not influence overall $\mathrm{mAb}$ transcytosis to the basolateral side. Since neither apical surface $p \mathrm{H}$ nor mAb FcRn affinity affected internalization or transcytosis obtained at saturating concentrations ( $\geq 10$ fold greater than the surface binding affinity), this suggests that a non-receptor mediated process was involved in $\mathrm{mAb}$ apical internalization. Although apical acidic $p \mathrm{H}$ conditions to enhance transcytosis are documented in human FcRn transfected epithelial cells in vitro $(13,33)$, it is mostly accepted that, once inside the cell, the acidic $p \mathrm{H}$ in endosomes enables FcRn-mAb binding and transcytosis. In previous reports, surface receptor saturating concentrations (e.g. $200 \mu \mathrm{g} / \mathrm{ml} \mathrm{IgG;}$ (32)) resulted in internalization, similar to this report. Thus non-receptor mediated endocytosis is a mechanism of $\mathrm{mAb}$ uptake in both adult, as well as neonatal (16), enterocytes. Non-receptor mediated endocytosis of $\mathrm{mAb}$ that is slow and rate limiting, prior to FcRn binding within the endosome and transcytosis, could limit uptake of $\mathrm{mAb}$ from the intestinal lumen observed in monkeys in vivo.

An unexpected finding of the present study was the identification of sub-population of EE cells that express FcRn with CCK8, gastrin in the stomach and GLP-1 and GLP-2 in the small intestine. FCRn expression was noted previously in crypt cells in small intestinal tissue from patients undergoing gastric by-pass (12) but were not previously identified as being enteroendocrine cells specifically. Interestingly, extensive colocalization was noted in the intestine where $F_{C} R n$ was expressed in L-cells (i.e. those that express GLP-1 and GLP2) and in the stomach, where FcRn was expressed in G cells (i.e. those that express gastrin) and CCK cells. Thus, FCRn was not limited in expression to a specific cell type (i.e. incretin cells versus CCK expressing cells) nor to EE cells in a specific region (i.e. intestine versus stomach). FcRn expression may be a fundamental property of these cells that reveals new functionalities for FCRn related to endocrine-immune interactions and currently unkown. In terms of delivery though, the novel finding of FcRn expression in these cells provides opportunities for targeting of mAb to enteroendocrine cells. Fc engineering to enhance $\mathrm{FcRn}$ internalization of $\mathrm{mAb}$ for recycling rather than transcytosis may be useful in this regard and has been reported previously (34). However, additional research would have to be done to determine is this will become a viable strategy for metabolic disease therapeutics.

\section{ACKNOWLEDGMENTS AND DISCLOSURES}

We acknowledge the outstanding quality of immunohistochemistry performed by Steve Bernstein and Marko Sldanov, Qualtek Molecular Labs, Goleta, CA, and the ex vivo human intestinal Ussing chamber work performed by Vatsala Naageshwaran and Fany B. Guerra, Absorption Systems, Exton PA.

All investigators are employees of Johnson \& Johnson and have no other conflict of interest to disclose.

Open Access This article is distributed under the terms of the Creative Commons Attribution License which permits any use, distribution, and reproduction in any medium, provided the original author(s) and the source are credited.

\section{REFERENCES}

1. Rodewald R, Kraehenbuhl JP. Receptor-mediated transport of IgG. J Cell Biol. 1984;99(1 Pt 2):159s-64s.

2. Simister NE, Rees AR. Isolation and characterization of an FC receptor from neonatal rat small intestine. Eur J Immunol. 1985;15(7):733-8.

3. Jakoi ER, Cambier J, Saslow S. Transepithelial transport of maternal antibody: purification of $\mathrm{IgG}$ receptor from newborn rat intestine. J Immunol. 1985;135(5):3360-4.

4. Berryman M, Rodewald R. Beta 2-microglobulin co-distributes with the heavy chain of the intestinal IgG-Fc receptor throughout the transepithelial transport pathway of the neonatal rat. J Cell Sci. 1995;108(Pt 6):2347-60.

5. Gastinel LN, Simister NE, Bjorkman PJ. Expression and crystallization of a soluble and functional form of an Fc receptor related to class I histocompatibility molecules. Proc Natl Acad Sci U S A. 1992;89(2): 638-42.

6. Telleman P, Junghans RP. The role of the Brambell receptor (FcRB) in liver: protection of endocytosed immunoglobulin $\mathrm{G}(\mathrm{IgG})$ from catabolism in hepatocytes rather than transport of $\operatorname{IgG}$ to bile. Immunology. 2000;100(2):245-51.

7. Martin MG, Wu SV, Walsh JH. Ontogenetic development and distribution of antibody transport and $\mathrm{Fc}$ receptor mRNA expression in rat intestine. Dig Dis Sci. 1997;42(5): 1062-9. 
8. Benlounes N, Chedid R, Thuillier F, Desjeux JF, Rousselet F, Heyman M. Intestinal transport and processing of immunoglobulin $\mathrm{G}$ in the neonatal and adult rat. Biol Neonate. 1995;67(4):254-63.

9. Kliwinski C, Cooper PR, Perkinson R, et al. Contribution of FcRn binding to intestinal uptake of IgG in suckling rat pups and human FcRn-transgenic mice. Am J Physiol Gastrointest Liver Physiol. 2013;304(3):G262-70.

10. Israel EJ, Taylor S, Wu Z, et al. Expression of the neonatal $\mathrm{FC}_{\mathrm{C}}$ receptor, $\mathrm{FcRn}$, on human intestinal epithelial cells. Immunology. 1997;92(1):69-74

11. Shah U, Dickinson BL, Blumberg RS, Simister NE, Lencer WI, Walker WA. Distribution of the IgG Fc receptor, FcRn, in the human fetal intestine. Pediatr Res. 2003;53(2):295-301.

12. Dickinson BL, Badizadegan K, Wu Z, et al. Bidirectional FcRndependent IgG transport in a polarized human intestinal epithelial cell line. J Clin Investig. 1999;104(7):903-11.

13. Claypool SM, Dickinson BL, Yoshida M, Lencer WI, Blumberg RS. Functional reconstitution of human FcRn in Madin-Darby canine kidney cells requires co-expressed human beta 2-microglobulin. J Biol Chem. 2002;277(31):28038-50.

14. Low SC, Nunes SL, Bitonti AJ, Dumont JA. Oral and pulmonary delivery of FSH-Fc fusion proteins via neonatal Fc receptor-mediated transcytosis. Hum Reprod. 2005;20(7):1805-13.

15. Norin KE, Midtvedt T, Gustafsson BE. Influence of intestinal microflora on the tryptic activity during lactation in rats. Lab Anim. 1986;20(3):234-7.

16. Baba R, Fujita M, Tein CE, Miyoshi M. Endocytosis by absorptive cells in the middle segment of the suckling rat small intestine. Anat Sci Int. 2002;77(2):117-23.

17. Udall JN, Pang K, Fritze L, Kleinman R, Walker WA. Development of gastrointestinal mucosal barrier. I. The effect of age on intestinal permeability to macromolecules. Pediatr Res. 1981;15(3):241-4.

18. Bitonti AJ, Dumont JA, Low SC, et al. Pulmonary delivery of an erythropoietin $\mathrm{Fc}$ fusion protein in non-human primates through an immunoglobulin transport pathway. Proc Natl Acad Sci U S A. 2004;101(26):9763-8.

19. Kuo TT, Aveson VG. Neonatal Fc receptor and IgG-based therapeutics. MAbs. 2011;3(5):422-30

20. Suzuki T, Ishii-Watabe A, Tada M, et al. Importance of neonatal $\mathrm{FcR}$ in regulating the serum half-life of therapeutic proteins containing the Fc domain of human IgG1: a comparative study of the affinity of monoclonal antibodies and Fc-fusion proteins to human neonatal FCR. J Immunol. 2010;184(4):1968-76.
21. Horton S, Walsh C, Emery P. Certolizumab pegol for the treatment of rheumatoid arthritis. Expert Opin Biol Ther. 2012;12(2): 235-49.

22. Roopenian DC, Akilesh S. FcRn: the neonatal Fc receptor comes of age. Nat Rev Immunol. 2007;7(9):715-25.

23. Yeung YA, Leabman MK, Marvin JS, et al. Engineering human IgGl affinity to human neonatal Fc receptor: impact of affinity improvement on pharmacokinetics in primates. J Immunol. 2009;182(12):7663-71.

24. Shields RL, Namenuk AK, Hong K, et al. High resolution mapping of the binding site on human IgG1 for $\mathrm{F}_{\mathrm{C}}$ gamma RI, Fc gamma RII, FC gamma RIII, and FcRn and design of IgGl variants with improved binding to the Fc gamma R. J Biol Chem. 2001;276(9):6591-604.

25. Firan M, Bawdon R, Radu C, et al. The MHC class I-related receptor, $\mathrm{FcRn}$, plays an essential role in the maternofetal transfer of gamma-globulin in humans. Int Immunol. 2001;13(8):993-1002.

26. Zalevsky J, Chamberlain AK, Horton HM, et al. Enhanced antibody half-life improves in vivo activity. Nat Biotechnol. 2010;28(2):157-9.

27. Bravman T, Bronner V, Lavie K, Notcovich A, Papalia GA, Myszka DG. Exploring "one-shot" kinetics and small molecule analysis using the ProteOn XPR36 array biosensor. Anal Biochem. 2006;358(2):2818.

28. Ladner RD, Lynch FJ, Groshen S, et al. dUTP nucleotidohydrolase isoform expression in normal and neoplastic tissues: association with survival and response to 5-fluorouracil in colorectal cancer. Cancer Res. 2000;60(13):3493-503.

29. Ageyama N, Shibata H, Narita H, et al. Specific gravity of whole blood in cynomolgus monkeys (Macaca fascicularis), squirrel monkeys (Saimiri sciureus), and tamarins (Saguinus labiatus) and total blood volume in cynomolgus monkeys. Contemp Top Lab Anim Sci. 2001;40(3):33-5.

30. Blumberg RS. Receptor specific transepithelial transport of therapeutics. US Patent Office 2009; (US patent 7,547,436B2):1-26.

31. Swartz MA. The physiology of the lymphatic system. Adv Drug Deliv Rev. 2001;50(1-2):3-20.

32. Sato K, Nagai J, Mitsui N, Ryoko Y, Takano M. Effects of endocytosis inhibitors on internalization of human IgG by Caco-2 human intestinal epithelial cells. Life Sci. 2009;85(23-26):800-7.

33. Claypool SM, Dickinson BL, Wagner JS, et al. Bidirectional transepithelial IgG transport by a strongly polarized basolateral membrane Fcgamma-receptor. Mol Biol Cell. 2004;15(4):1746-59.

34. McCarthy KM, Lam M, Subramanian L, et al. Effects of mutations in potential phosphorylation sites on transcytosis of FcRn. J Cell Sci. 2001;114(Pt 8):1591-8. 